Tohoku J. Exp. Med., 2009, 219, 169-176

\title{
WT1 mRNA Level in Peripheral Blood Is a Sensitive Biomarker for Monitoring Minimal Residual Disease in Acute Myeloid Leukemia
}

\author{
Yuichi Sakamoto, ${ }^{1}$ Yasushi Mariya, ${ }^{1}$ Sumiko Sasaki, ${ }^{1}$ Ryuichi Teshiromori, ${ }^{1}$ \\ Toshiyuki Oshikiri, ${ }^{1}$ Megumi Segawa, ${ }^{1}$ Kazuto Ogura, ${ }^{2}$ Tomoaki Akagi, ${ }^{2}$ \\ Koumei Kubo, ${ }^{2}$ Mitsuomi Kaimori ${ }^{3}$ and Tadao Funato ${ }^{4}$ \\ ${ }^{1}$ Department of Laboratory Medicine, Aomori Prefectural Central Hospital, Aomori, Japan \\ ${ }^{2}$ Department of Hematology, Aomori Prefectural Central Hospital, Aomori, Japan \\ ${ }^{3}$ Department of Pathology, Aomori Prefectural Central Hospital, Aomori, Japan \\ ${ }^{4}$ Division of Healthcare Economics and Quality Management, Tohoku Fukushi University, Sendai, Japan
}

\begin{abstract}
The Wilms' tumor gene 1 (WT1) encodes a transcription factor that is involved in normal cellular development and cell survival. WT1 mRNA is overexpressed in the minimal residual disease (MRD) of patients with hematopoietic malignancy patients, particularly acute myeloid leukemia (AML). MRD represents the condition with the low levels of leukemia cells in the bone marrow and is known as a sign of recurrence. In hematopoietic malignancies, definition of remission is based on the lack of MRD at submicroscopic level. Between December 2005 and June 2008, we started to measure WT1 mRNA levels in the peripheral blood (PB) from patients by quantitative real-time PCR in Aomori Prefectural Central Hospital. Three hundreds and eight samples from 95 patients were evaluated. The patients included AML (55 patients), acute lymphoblastic leukemia (11), myelodysplastic syndrome (20), malignant lymphoma (5), chronic myeloid leukemia (1), prostatic carcinoma (1), and leukopenia (2). Among the 55 AML patients, 21 patients were pretreated with remission induction therapy. In the clinical course of 21 patients, timely therapeutic approaches could be started for relapse by the early detection of WT1 mRNA overexpression before the morphological findings were apparent. Monitoring WT1 mRNA is helpful to identify patients at high-risk relapse. High overall survival rate (71.2\%, 15/21, median: 24.6 months, range 1.1-35.6 months) was achieved in 3 years. The overall survival rate of 34 post-treatment patients was $61.7 \%$ (median: 23.5 months, range 0.13-126.5 months after treatment start). In conclusion, the WT1 mRNA level is a sensitive biomarker for monitoring MRD. ——Wilms' tumor gene 1; minimal residual disease; acute leukemia; hematopoietic stem cell transplantation; Real-time Quantitative PCR.

Tohoku J. Exp. Med., 2009, 219 (2), 169-176. 일 2009 Tohoku University Medical Press
\end{abstract}

The Wilms' tumor gene 1 (WT1) was discovered as a causative gene of the infant Wilms' tumor (Call et al. 1992). WT1 exists in chromosome 11p13q, consisting of ten exons, and the transcript restrictor of zinc finger type of 52-54 kDa. WT1 encodes a transcription factor that is required for normal cellular development and cell survival.

The WT1 is highly expressed in several hematopoietic tumors and various other types of solid tumors, for example, melanoma, renal cell carcinoma, and lung, breast, testicular, and ovarian cancers (Miwa et al. 1992; Campbell et al. 1998). Especially in acute leukemia, WT1 expression is recognized as a marker of existing leukemic cells. Call et al. (1992) reported the expression of WT1 mRNA in leukemic cell. Miwa et al. (1992) reported the expression of WT1 mRNA in patients with acute myeloid leukemia (AML) detected by the Northern blot analysis. Overexpression of WT1 mRNA at diagnosis was also seen in various hematopoietic malignancies, including AML (Miyoshi et al. 2002; Ueda et al. 2003; Sotobori et al. 2006). The level of WT1 mRNA was reported to reflect the presence of minimal residual disease (MRD) in acute myeloid leukemia nevertheless the morphological findings are remaining in complete remission (CR) (Candoni et al. 2008; Cilloni et al. 2008). Quantification of WT1 mRNA in PB sample can be useful for detecting MRD and predicting the relapse of AML after allogeneic hematopoietic stem cell transplant (HSCT) regardless of the leukemina type.

In turn, detection of leukemic chimeric gene with chromosomal translocation is useful in diagnosis of AML (Inoue et al. 1994; Cilloni et al. 2002; Trka et al. 2002; Ogawa et

Received March 10, 2009; revision accepted for publication August 26, 2009. doi:10.1620/tjem.219.169

Correspondence: Yuichi Sakamoto, Department of Laboratory Medicine, Aomori Prefectural Central Hospital, 2-1-1 Higashi-

tsukurimichi, Aomori-shi, Aomori, 0308553, Japan.

e-mail: 97036ys@jichi.ac.jp 
al. 2003). However, most of AML cases do not have a sensible marker of MRD after morphological remission. If disease recurrence is apparent before a morphological relapse, timely therapeutic approaches could be started for relapse, such as immunosuppressive therapy or the use of donor lymphocyte infusion (DLI).

We started to measure WT1 mRNA in PB samples using the real-time quantitative PCR method in our hospital in December 2005. The purpose of this study is to investigate whether the WT1 mRNA value is a biomarker detecting MRD in the patient with hematopoietic malignancy, using a real-time quantitative PCR technique.

\section{Materials and Methods}

\section{Patients and Materials}

PB sample from out- or in-patients diagnosed and treated in the department of hematology in Aomori Prefectural Central Hospital from December 2005 to June 2008 were collected, and then processed to extract total RNA described below. The PB samples were collected at diagnosis, during therapy and during post-therapy follow-up. Most of them were obtained as part of diagnostic procedures. Samples from all 95 patients (348 samples) were collected at the department of hematology in Aomori Prefectural Central Hospital between October 2005 and July 2008. Ninety-five patients (samples) included 55 subjects (294 samples) of AML, 11 (42 samples) of acute lymphoblastic leukemia (ALL), 20 (59 samples) of myelodysplastic syndrome (MDS), 5 (8 samples) of malignant lymphoma, 1 (1 sample) of chronic myeloid leukemia (CML), 1 (1 sample) of prostatic carcinoma, and 2 (2 samples) of leukopenia (Table 1). Fifty-five AML patients included 21 patients, who were pretreated (pre-remission induction therapy) (Table 2). In 34 post-treatment patients, overall survival was observed regardless of sample collection. The protocol was approved by the ethical committee in Aomori Prefectural Central Hospital.

\section{Clinical criteria and treatment strategy}

The staff of the department of hematology treated the patients according to the JALSG protocol (http://www.jalsg.jp/index.html). French-American-British (FAB) classification was used for morphological diagnosis. The bone marrow was examined and the ratio of the blasts was determined for judgment of the treatment effect. CR was considered by standard criteria, based on morphological findings

Table 1. Characteristics of patients.

\begin{tabular}{lcc}
\hline \multicolumn{1}{c}{ Diseases } & No. of patients & No. of samples \\
\hline AML & 55 & 294 \\
ALL & 11 & 42 \\
MDS & 20 & 59 \\
Malignant lymphoma & 5 & 8 \\
CML & 1 & 1 \\
Proststic carcinoma & 1 & 1 \\
Leukopenia & 2 & 2 \\
\hline Total & 95 & 348 \\
\hline
\end{tabular}

Samples were collected at department of hematology in Aomori Prefectural Central Hospital between October 2005 and July 2008. by the presence of less than $5 \%$ blasts in the bone marrow. Patients were divided into two groups. One is the pretreatment group that received no treatment at diagnosis, and the other is the treated group who had already received various types of treatment.

The samples from AML patients in the pretreatment group were analyzed, and the percentage of blasts was compared with the level of WT1 mRNA. The percentage of blasts was compared with the level of WT1 mRNA. The change of treatment strategy and the result based on the level of the WTI mRNA were examined. OS in the pretreatment group in AML patients was also estimated.

\section{RNA extraction and cDNA synthesis}

The PB from the patients was processed with RBC Lysis Buffer (Roche Diagnostics, Basel, Switzerland). Total RNA was extracted using High Pure RNA Isolation Kit (Roche), following the manufacturer's instructions. $\mathrm{PB}$ was stirred at $25^{\circ} \mathrm{C}$ for $10 \mathrm{~min}$, and total RNA was extracted. Quality of RNA was checked by spectrophotometer: optical density instrument: Gene Quant pro (GE Healthcare BioSciences, Tokyo, Japan). One-percent agarose gel electrophoresis of RNA was done. cDNA synthesis: reverse transcription (RT) step was performed with Transcripter First Strand cDNA Synthesis Kit (Roche) according to the manufacturer's instruction. Transcriptase reaction buffer, transcriptase, deoxynucleotide mix, random hexamer primer and RNase inhibitor (all Roche) were added to total RNA. Total mixture was incubated at $55^{\circ} \mathrm{C}$ for $30 \mathrm{~min}$. Transcriptase was inactivated at $85^{\circ} \mathrm{C}$ for $5 \mathrm{~min}$. The residue of extracted RNA and cDNA were stocked at $-80^{\circ} \mathrm{C}$.

\section{Real-time quantitative PCR of WT1}

Quantitative real-time polymerase chain reaction (RQ-PCR) reactions and fluorescence measurements were performed on the LightCycler2.0 instrument (Roche). LightCycler primer \& probe set (Roche) was used for quantitative assessment. Primers for WT1 (Roche, GenBank Accession: NM_000378) and glyceraldehyde-3phosphate dehydrogenase (GAPDH: Roche, GenBank Accession: M33197) and LightCyler-FastStart DNA Master Hybridization Probe (Roche) were used. The fluorescent probe was labeled with reporter dye at the $5^{\prime}$-end and with the quencher dye at the $3^{\prime}$-end. All assessments were carried out in duplicate with appropriate negative controls. PCR was performed on the LightCycler2.0 instrument (Roche) as follows: denaturation at $95^{\circ} \mathrm{C}$ for $10 \mathrm{~min} ; 40$ cycles of denaturation at $72^{\circ} \mathrm{C}$ for $5 \mathrm{sec}$; annealing at $95^{\circ} \mathrm{C}$ for $10 \mathrm{~s}$; extension at $62^{\circ} \mathrm{C}$ for $15 \mathrm{~s}$,

Table 2. No. of pretreatment AML patients.

\begin{tabular}{lc}
\hline AML $(n=55)$ & Pre-remission induction therapy \\
\hline M1 & $0 / 2$ \\
M2 & $9 / 20$ \\
M3 & $3 / 5$ \\
M4 & $3 / 9$ \\
M5 & $1 / 4$ \\
M6 & $0 / 1$ \\
prior MDS & $4 / 8$ \\
Others & $1 / 6$ \\
\hline Total & $21 / 55$ \\
\hline
\end{tabular}

Fifty-five patients included 21 patients who were untreated (pre-remission induction therapy). 
and final extension at $40^{\circ} \mathrm{C}$ for $30 \mathrm{~s}$. The result data were treated with LightCycler Software (Roche).

Normal range of WT1 mRNA expression levels was determined in 50 healthy subjects ( 25 males and 25 females) and normalized to the GAPDH as an internal control. Calculations were based on the average level derived for each RNA preparation of $1 \mu \mathrm{g}$. The average GAPDH of 50 healthy subjects was $2.8 \times 10^{6}$ copies/ $\mu$ g RNA. The corrective quantitative value was decided by this equation ([WT1/ GAPDH $] \times 2.8 \times 10^{6}$ copies $/ \mu$ g RNA). The cutoff value was decided as 150 copies $/ \mu$ g RNA in PB. Samples with $W T 1$ expression levels above the cutoff value were judged as 'WT1 overexpression'. The data less than the cutoff value were judged as detection limit.

\section{Results}

Ninety-five patients included 55 subjects with AML, 11 with ALL, 20 with MDS, 5 with malignant lymphoma, 1 with CML, 1 with prostatic carcinoma, and 2 with leukope-

Table 3. Expression level at diagnosis.

\begin{tabular}{lcc}
\hline \multicolumn{1}{c}{ WT1 mRNA } & $\begin{array}{c}\text { No. of patients } \\
(\%)\end{array}$ & $\begin{array}{c}\text { Median } \\
\text { (copies/ } \mu \mathrm{gRNA})\end{array}$ \\
\hline High expression* & $18 / 21(85.7 \%)$ & 18,000 \\
Low expression & $3 / 21(13.0 \%)$ & 52 \\
\hline
\end{tabular}

Eighteen patients $(85.7 \%)$ over-expressed WT1 mRNA level at diagnosis (median: 18,000 copies/ $\mu$ g RNA, range 240-370,000). *high $\geq 150$ copies/ $\mu$ g RNA nia (Table 1).

In 40 non-AML patients, after morphological diagnosis, most of samples were not collected continuously. In only 23 patients that were continuously observed, WT1 mRNA overexpression was seen in 11 patients. There was no apparent correlation with MRD (data not shown).

Fifty-five AML patients were divided into 34 posttreatment patients and 21 pretreatment patients. In the post-

Table 4. CR rate of AML patients.

\begin{tabular}{lc}
\hline \multicolumn{2}{c}{ CR } \\
\hline AML \\
M2 \\
M3 \\
M4 \\
M5 \\
Prior MDS \\
Others \\
Total \\
\multicolumn{2}{c}{ The significant difference in levels of WT1 } \\
expression is shown. Overall survival rate of 21 \\
patients in AML at this study was $71.2 \%$. \\
Eighteen patients of 21 patients $(85.7 \%)$ \\
achieved CR after first remission induction \\
therapy.
\end{tabular}

Table 5. The characteristics of 21 AML patients.

\begin{tabular}{|c|c|c|c|c|c|c|c|}
\hline Patient no. & Age & Sex & Diagnosis & Therapy & Prognosis & First CR & Group \\
\hline 1 & 53 & M & AML (M4) & PBSCT & Dead & $\mathrm{CR}$ & $\mathrm{D}$ \\
\hline 2 & 22 & M & AML/MLD prior MDS & $\mathrm{BMT}+\mathrm{PBSCT}$ & Survive & $\mathrm{CR}$ & E \\
\hline 3 & 70 & M & AML/MLD prior MDS & Ara-C/ACR & Relapse \& dead & $\mathrm{CR}$ & $\mathrm{D}$ \\
\hline 4 & 31 & M & AML (M3) & ATRA & Survive & $\mathrm{CR}$ & $\mathrm{C}$ \\
\hline 5 & 53 & M & AML (M4) & CBT & Survive & $\mathrm{CR}$ & E \\
\hline 6 & 28 & M & AML (M4) & Ara-C/IDR & Dead & non $\mathrm{CR}$ & A \\
\hline 7 & 81 & $\mathrm{~F}$ & AML (M2) & Ara-C/VP-16 & Relapse \& dead & $\mathrm{CR}$ & $\mathrm{D}$ \\
\hline 8 & 70 & M & AML (M5b) & Ara-C/IDR & Survive & $\mathrm{CR}$ & $\mathrm{C}$ \\
\hline 9 & 71 & M & AML/Acute leukemia of ambiguous lineage & CY, DNR, VCR & Dead & non $\mathrm{CR}$ & A \\
\hline 10 & 68 & M & AML (M2) & Ara-C/IDR & Survive & $\mathrm{CR}$ & $\mathrm{C}$ \\
\hline 11 & 40 & $\mathrm{~F}$ & AML (M2) & PBSCT & Survive & $\mathrm{CR}$ & $\mathrm{C}$ \\
\hline 12 & 58 & M & AML (M2) & Ara-C/IDR & Survive & $\mathrm{CR}$ & $\mathrm{C}$ \\
\hline 13 & 78 & M & AML (M2) & Ara-C/DNR & Survive & non $\mathrm{CR}$ & B \\
\hline 14 & 69 & $\mathrm{~F}$ & AML/MLD prior MDS monosomy 7 & Ara-C/ACR & Survive & $\mathrm{CR}$ & $\mathrm{C}$ \\
\hline 15 & 60 & $\mathrm{~F}$ & AML (M3) & ATRA & Survive & $\mathrm{CR}$ & $\mathrm{C}$ \\
\hline 16 & 40 & M & AML/MLD prior MDS & BMT & Survive & CR & $\mathrm{E}$ \\
\hline 17 & 42 & M & AML (M3) & ATRA & Survive & $\mathrm{CR}$ & $\mathrm{C}$ \\
\hline 18 & 79 & $\mathrm{~F}$ & AML (M2) & BMT & Survive & $\mathrm{CR}$ & $\mathrm{C}$ \\
\hline 19 & 34 & M & AML (M2) CNS infiltration & BMT & Survive & $\mathrm{CR}$ & $\mathrm{E}$ \\
\hline 20 & 43 & M & AML (M2) & Ara-C/IDR & Survive & $\mathrm{CR}$ & $\mathrm{C}$ \\
\hline 21 & 59 & $\mathrm{~F}$ & AML (M2) & PBSCT & Survive & $\mathrm{CR}$ & E \\
\hline
\end{tabular}

ACR, aclarubicin; Ara-C, cytarabine; ATRA, all-trans retinoic acid; BMT, bone marrow transplantation; CBT, cord blood transplantation; CR, complete remission; CY, cyclophosphamide; DNR, daunorubicin; IDR, idarubicin; MLD, multilineage dysplasia; PBSCT, peripheral blood stem cell transplantation; VCR, vincristine; VP-16, etoposide. 
treatment group, 30 patients achieved morphological CR. Average level of WT1 mRNA expression during morphological CR was 80.4 copies/ $\mu$ g RNA (range 50-430). There was discrepancy between morphological CR and WT1 mRNA in 2 patients (data not shown). OS rate of 34 posttreatment patients was $61.7 \%$ (median: 23.5 months, range 0.13-126.5 months after treatment start).

Eighteen AML patients pretreated with remission induction therapy overexpressed WT1 mRNA at diagnosis (18/21: 85.7\%, median: 18,000 copies/ $\mu$ g RNA, range 240-370,000). Overexpressed WT1 mRNA at diagnosis of AML was more than 150 copies/ $\mu$ g RNA in PB. Only 3 patients had low expression levels at diagnosis (Table 3 ). The significant difference in levels of WT1 mRNA expression is shown. OS rate of 21 patients with AML in 3 years was 71.2\% (median: 24.6 months, range 1.1-35.6 months). Eighteen of 21 patients $(85.7 \%)$ achieved CR after first remission induction therapy (Table 4).

The characteristics of 21 AML patients are shown in Table 5. Two patients did not achieve CR and WT1 mRNA level remained over the cutoff value (group A). One patient did not achieve CR and WT1 mRNA level was below the cutoff value (B). Ten patients achieved CR, but WTI mRNA level was over the cut-off value $(C)$. Three patients achieved CR with WT1 mRNA below the cut-off value, but WT1 mRNA subsequently rose above the cut-off value. The patients experienced AML relapse (D). Five patients achieved CR with WT1 mRNA below the cutoff value (E).

Patient no. 1 belongs to group D, with AML (M4) and 46XY. WT1 mRNA expression was still high though mor- phologic CR was achieved in the second month after starting treatment. HSCT was performed at the sixth month, and WT1 mRNA was lower than cutoff value. However, at the fourteenth month, sudden overexpession of WT1 mRNA was seen, and the patient relapsed with $73 \%$ blasts in BM analysis. WT1 mRNA level became low again after immunotherapy, but the patients relapsed at the twenty-second month and died (Fig. 1).

Patient no. 2 belongs to group E, with AML (M2), 46XY, and inv (17). WT1 mRNA before treatment was high with $20 \%$ blasts. After chemotherapy and HSCT was performed in 3 months, morphologic CR was achieved, and WT1 mRNA expression became low. At the twenty-fifth month, WT1 mRNA became high above the cutoff value. The patient was treated in a molecular relapse. A molecular CR was achieved again, and the patient survives to date (Fig. 2).

Patient no. 3 belongs to group D, associated with AML with multi-lineage dysplasia without prior MDS. At diagnosis WT1 mRNA was below the cutoff value, but the percentage of blasts was $34.5 \%$. After treatment WT1 mRNA level temporarily decreased, but suddenly rose with morphologic CR. The patient relapsed and died at the eighth month (Fig. 3).

\section{Discussion}

WT1 mRNA levels were measured in PB from hematopoietic malignancy patients in our hospital. WT1 mRNA from PB detected MRD more sharply than the morphological findings of bone marrow aspiration. It has been reported

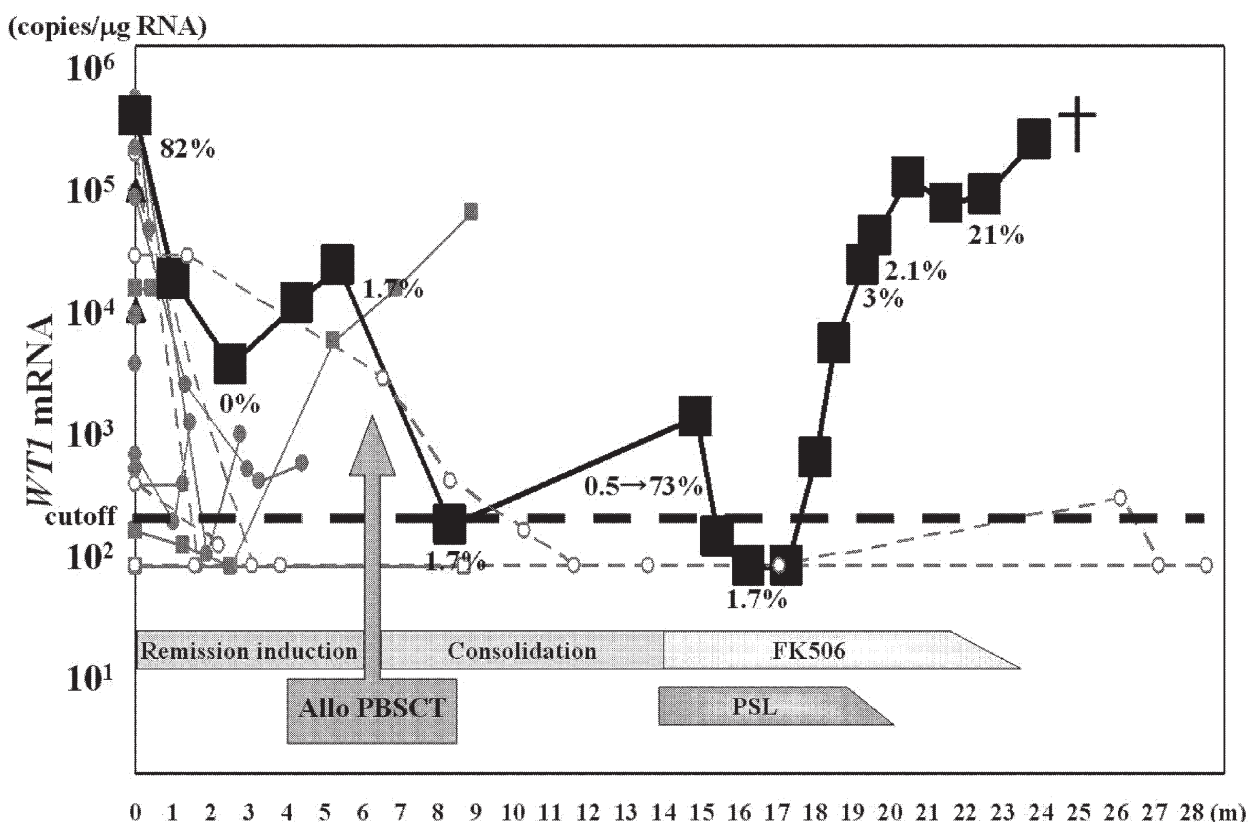

Fig. 1. Patient no. 1 experienced AML relapse after CR with WT1 mRNA below the cut-off value.

Filled square ( $\mathbf{\square}$ ) mark indicates the changes in WT1 mRNA level of Patient no. 1. The percentage below mark is blasts percentage in bone marrow at that time. For comparison, also shown are WT1 mRNA levels in other patients. Filled triangle $(\boldsymbol{\Delta})$, blank square $(\square)$, filled circle $(\bigcirc)$, filled gray square $(\square)$, and blank circle with dotted line $\left(-\bigcirc_{-}\right)$are the levels of other patients in group A, B, C, D, and E, respectively. Cut off value is 150 copies/ $\mu \mathrm{g}$ RNA. m: months, FK 506: tacrolimus, PSL: predonisolone. 


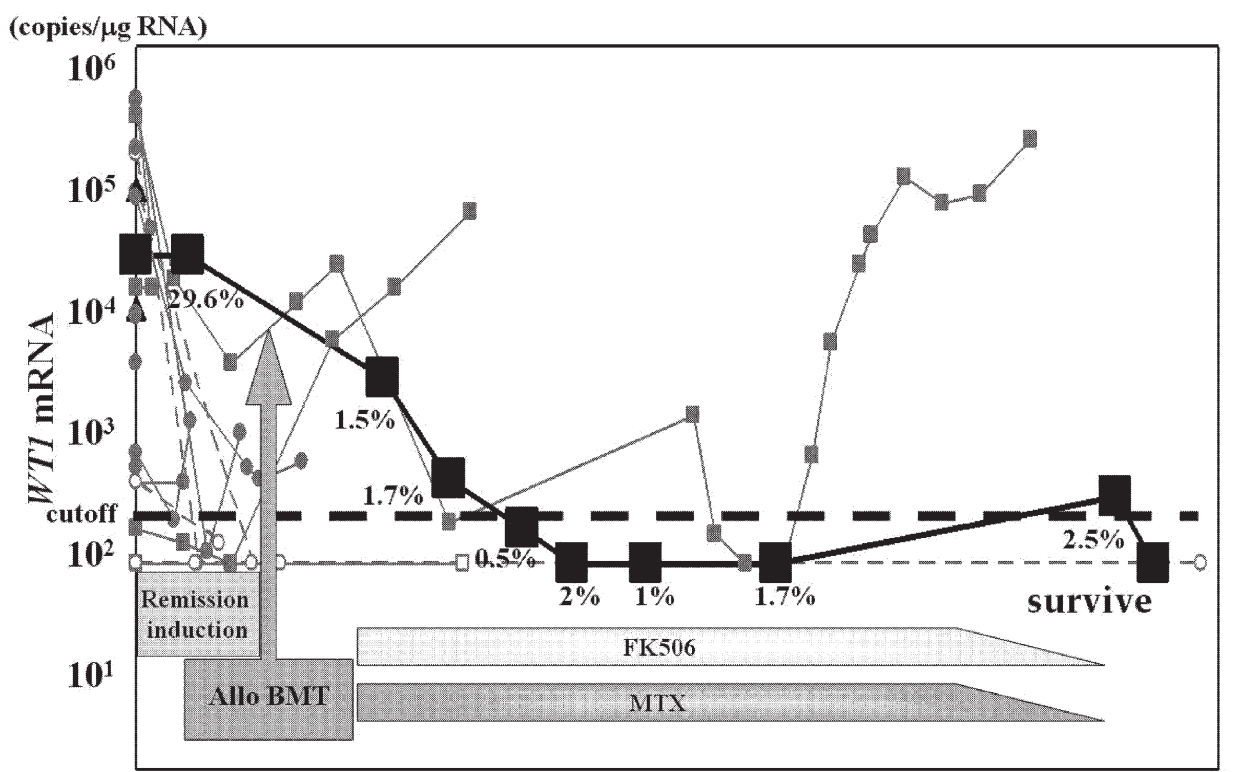

$\begin{array}{llllllllllllllllllllllllllllll}0 & 1 & 2 & 3 & 4 & 5 & 6 & 7 & 8 & 9 & 10 & 11 & 12 & 13 & 14 & 15 & 16 & 17 & 18 & 19 & 20 & 21 & 22 & 23 & 24 & 25 & 26 & 27 & 28 & (\mathrm{~m})\end{array}$

Fig. 2. Patient no. 2 achieved CR with $W T 1$ mRNA below the cutoff value.

Filled square ( $\mathbf{\square}$ ) mark indicates the changes in WT1 mRNA level of Patient no. 2. The percentage below mark is blasts percentage in bone marrow at that time. Filled triangle $(\mathbf{\Delta})$, blank square $(\square)$, filled circle $(\boldsymbol{O})$, filled gray square (口), and blank circle with dotted line (-O-) are the levels of other patients in group A, B, C, D, and E, respectively. m: months, BMT: bone marrow transplantation, FK 506: tacrolimus, MTX: methotrexate. Cut off value is $150 \mathrm{copies} / \mu \mathrm{g}$ RNA.

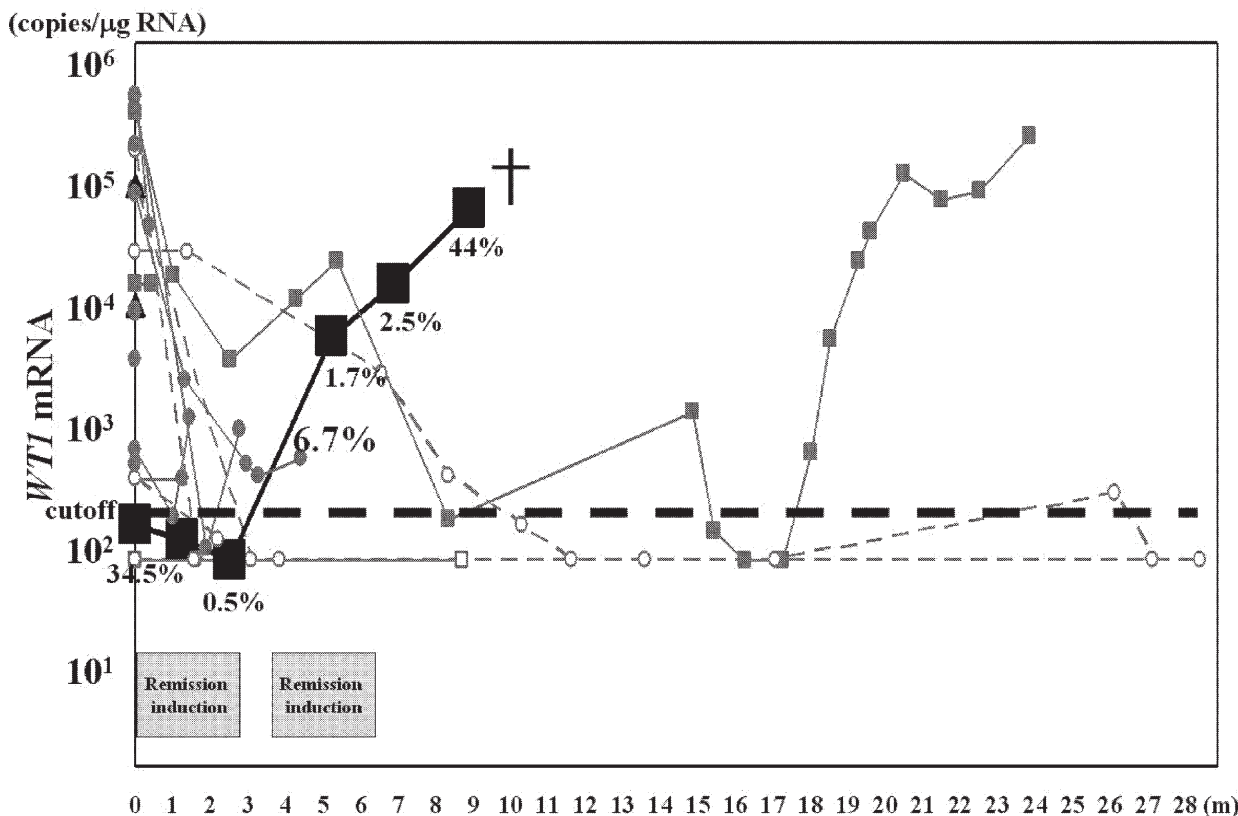

Fig. 3. Patient no. 3 experienced AML relapse.

Filled square ( $\mathbf{\square}$ ) mark indicates the changes in WT1 mRNA level of Patient no. 3. The percentage below mark is blasts percentage in bone marrow at that time. Filled triangle $(\mathbf{\Delta})$, blank square $(\square)$, filled circle $(\mathbf{O})$, filled gray square ( $\square$ ), and blank circle with dotted line (-○-) are the levels of other patients in group A, B, C, D, and E, respectively. Cut off value is 150 copies/ $\mu \mathrm{g}$ RNA. m: months. 
that WT1 mRNA expression is a general molecular marker in leukemia (Inoue et al. 1996; Cilloni et al. 2002, 2004, 2008; Lapillonne et al. 2006; Ommen et al. 2008). It is important to measure WT1 mRNA at any time, at diagnosis or in CR. Many authors reported WT1 mRNA monitoring showing definitive correlation for detecting MRD and relapse in the post-HSCT patients (Inoue et al. 1996, 1997; Cilloni et al. 2008), although some observed no correlation (Ogawa et al. 1998; Mizuta et al. 1999; Elmaagacli et al. 2000; Cilloni et al. 2003; Lapillonne et al. 2006; Candoni et al. 2008). When patients were in CR, all of the WT1 mRNA levels were within normal range. If the value of WTI mRNA changed to that above the cutoff value, then the patients frequently relapsed. As demonstrated in patients 1 and 3, when the WT1 mRNA overexpression is detected, the possibility of relapse is high in the patient even though morphologic CR is evident after chemotherapy or HSCT (Figs. 1 and 3 ).

Ommen et al. (2008) reported that their long-term WT1 mRNA monitoring had targeted more patients in CR than other past studies. They detected the relapse in $21 / 37$ patients by monitoring more patients and more frequently. In addition, Weisser et al. (2005) described that 569 samples (5 specimens from each patient) were measured and overexpression appeared in 16/42 patients before morphological or clinical relapse. In these studies, the utility of WT1 mRNA in linking with clinical information was emphasized.

The fusion gene assay for detecting specific molecular marker is not used in follow-up, because the sensitivity might be estimated low (Kern et al. 2008). Compared with fusion gene assays, WT1 mRNA seems less specific. But WT1 mRNA can diagnose the relapse before a clinical, histological, and immunological relapse occurs. By detecting MRD at the early stage, timely therapeutic approaches can be decided.

No correlation between WT1 mRNA and the MRD detection was described (Elmaagacli et al. 2000). Elmaagacli et al. (2000) evaluated patients with AML and ALL at various points during the clinical course of the disease. As different studies use different points and intervals to measure results, there is a lack of consensus for WT1 mRNA detecting MRD in some studies. Despite the controversy mentioned above, WT1 mRNA is recommended for evaluation of patients with AML after chemotherapy and HSCT.

The best way to use PB samples for detecting MRD is to evaluate median values of sequentially test results for three months (Candoni et al. 2008). The WT1 mRNA is always positive 3-4 months before clinical relapse. Both $\mathrm{BM}$ and $\mathrm{PB}$ are useful in patients with AML after the chemotherapy. BM samples every month could detect the relapse more sensitively than PB (Ommen et al. 2008). But, $\mathrm{PB}$ can be collected more frequently from the same patient than BM.

In Patient no. 2, when the WT1 mRNA overexpression at diagnosis is seen, the patient can be treated (Fig. 2). In our study, the PB sample is collected easily every month or every other month and the quality of sample is consistent between hospitals or when obtained by a general physician. The collection of PB samples avoids frequent and invasive bone marrow aspiration (BMA) (van der Velden et al. 2004). The examination was performed in duplicate and using total RNA minimizes the differences in results.

About $80 \%$ of the patients were reported to show WT1 mRNA overexpression at diagnosis is consistent with our results of $85.7 \%$. WT1 mRNA level was decreased following the treatment course. When WT1 mRNA level was rising, molecular relapse was suspected. As shown in Patient no. 3, even if WT1 mRNA expression was low at diagnosis, WT1 mRNA level rose during the follow up. WT1 mRNA is considered important information at any point during follow up.

There is a discrepancy between WT1 mRNA quantification and clinical relapse. The influence from 8 bp deletion in exon 7 and a single nucleotide polymorphism (SNP: rs 16754) are pointed out (Nyvold et al. 2006). If the probe and primer design is appropriate, WT1 mRNA cannot be detected.

In present study the threshold is 150 copies/ $\mu \mathrm{g}$ RNA. It is a proper setting because there was no overexpression in healthy volunteers or in patients with $\mathrm{CR}$ without relapse after chemotherapy. But the CD34 positive cell in BM expresses WT1 mRNA. Therefore the value of WT1 mRNA in BM samples is often high in the background, and this can possibly interfere with detection of relapse. WT1 mRNA expression must be observed carefully to judge false positive. Judging the presence of relapse is not so simple because there can be a false positive. Ommen et al. (2008) recommend that a positive result should be elevated two or times to be interpreted as molecular relapse.

In other diseases, for example MDS and ALL, there is a report that detects MRD (Cilloni and Saglio 2004; Neale et al. 2004). In this study we examined AML patients, although the samples of MDS and ALL patients were also collected as shown in Fig. 1. Further estimation is needed for these hematopoietic malignancies in the future.

Currently, the importance of WT1 mRNA quantification by real-time quantitative PCR as a MRD detecting marker was confirmed. WT1 mRNA is useful not only in detecting MRD but also at diagnosis. MRD has been detected by WT1 mRNA rising at the early stage in the AML patients after chemotherapy and HSCT. When WT1 mRNA rises gradually, adjustment and discontinuance of the immunosuppressive agent and the pre-emptive DLI should be considered. MRD are vitally important information for the patient with normal morphologic findings of BM. Overall survival time is longer than in the patient with WT1 mRNA overexpression and the prognosis can improve.

A single assay of WT1 mRNA can be used to follow a lot of patients. This technique has been already established in our hospital, and will improve the standardization for the commercial kit in the future. 


\section{Conclusion}

In present study, we investigated the clinical utility of WT1 mRNA in 21 AML patients. WT1 mRNA detected the relapse before the morphologic findings were apparent. The WT1 mRNA level is a sensitive biomarker for monitoring MRD in the hematopoietic malignancy patients.

\section{References}

Call, K.M., Glaser, T., Ito, C.Y., Buckler, A.J., Pelletier, J., Haber, D.A., Rose, E.A., Kral, A., Yeger, H., Lewis, W.H., Jones, C. \& Housman, D.E. (1992) Isolation and characterization of a zinc finger polypeptide gene at the human chromosome 11 Wilms' tumor locus. Cell, 60, 509-520.

Campbell, C.E., Kuriyan, N.P., Rackley, R.R., Caulfield, M.J., Tubbs, R., Finke, J. \& Williams, B.R. (1998) Constitutive expression of the Wilms tumor suppressor gene (WT1) in renal cell carcinoma. Int. J. Cancer, 78, 182-188.

Candoni, A., Tiribelli, M., Toffoletti, E., Cilloni, D., Chiarvesio, A., Michelutti, A., Simeone, E., Pipan, C., Saglio, G. \& Fanin, R. (2008) Quantitative assessment of WT1 gene expression after allogeneic stem cell transplantation is a useful tool for monitoring minimal residual disease in acute myeloid leukemia. Eur. J. Haematol., 82, 61-68.

Cilloni, D., Gottardi, E., De Micheli, D., Serra, A., Volpe, G., Messa, F., Rege-Cambrin, G., Guerrasio, A., Divona, M., Lo Coco, F. \& Saglio, G. (2002) Quantitative assessment of WT1 expression by real time quantitative PCR may be a useful tool for monitoring minimal residual disease in acute leukemia patients. Leukemia, 16, 2115-2121.

Cilloni, D., Gottardi, E., Fava, M., Messa, F., Carturan, S., Busca, A., Guerrasio, A. \& Saglio, G. (2003) Usefulness of quantitative assessment of the WT1 gene transcript as a marker for minimal residual disease detection. Blood, 102, 773-774.

Cilloni, D., Messa, F., Arruga, F., Defilippi, I., Gottardi, E., Fava, M., Carturan, S., Catalano, R., Bracco, E., Messa, E., Nicoli, P., Diverio, D., Sanz, M.A., Martinelli, G., Lo-Coco, F. \& Saglio, G. (2008) Early prediction of treatment outcome in acute myeloid leukemia by measurement of WT1 transcript levels in peripheral blood samples collected after chemotherapy. Haematologica, 93, 921-924.

Cilloni, D. \& Saglio, G. (2004) WT1 as a universal marker for minimal residual disease detection and quantification in myeloid leukemias and in myelodysplastic syndrome. Acta Haematol., 112, 79-84.

Elmaagacli, A.H., Beelen, D.W., Trenschel, R. \& Schaefer, U.W. (2000) The detection of wt-1 transcripts is not associated with an increased leukemic relapse rate in patients with acute leukemia after allogeneic bone marrow transplantation or peripheral blood stem cell transplantation. Bone Marrow Transplant., 25, 91-96.

Inoue, K., Ogawa, H., Sonoda, Y., Kimura, T., Sakabe, H., Oka, Y., Miyake, S., Tamaki, H., Oji, Y., Yamagami, T., Tatekawa, T., Soma, T., Kishimoto, T. \& Sugiyama, H. (1997) Aberrant overexpression of the Wilms tumor gene (WT1) in human leukemia. Blood, 89, 1405-1412.

Inoue, K., Ogawa, H., Yamagami, T., Soma, T., Tani, Y., Tatekawa, T., Oji, Y., Tamaki, H., Kyo, T., Dohy, H., Hiraoka, A., Masaoka, T., Kishimoto, T. \& Sugiyama, H. (1996) Longterm follow-up of minimal residual disease in leukemia patients by monitoring WT1 (Wilms tumor gene) expression levels. Blood, 88, 2267-2278.

Inoue, K., Sugiyama, H., Ogawa, H., Nakagawa, M., Yamagami, T., Miwa, H., Kita, K., Hiraoka, A., Masaoka, T. \& Nasu, K. (1994) WT1 as a new prognostic factor and a new marker for the detection of minimal residual disease in acute leukemia. Blood, 84, 3071-3079.
Kern, W., Haferlach, C., Haferlach, T. \& Schnittger, S. (2008) Monitoring of minimal residual disease in acute myeloid leukemia. Cancer, 112, 4-16.

Lapillonne, H., Renneville, A., Auvrignon, A., Flamant, C., Blaise, A., Perot, C., Lai, J.L., Ballerini, P., Mazingue, F., Fasola, S., Dehée, A., Bellman, F., Adam, M., Labopin, M., Douay, L., Leverger, G., Preudhomme, C. \& Landman-Parker, J. (2006) High WT1 expression after induction therapy predicts high risk of relapse and death in pediatric acute myeloid leukemia. J. Clin. Oncol., 24, 1507-1515.

Miwa, H., Beran, M. \& Saunders, G.F. (1992) Expression of the Wilms' tumor gene (WT1) in human leukemias. Leukemia, 6 , 405-409.

Miyoshi, Y., Ando, A., Egawa, C., Taguchi, T., Tamaki, Y., Tamaki, H., Sugiyama, H. \& Noguchi, S. (2002) High expression of Wilms' tumor suppressor gene predicts poor prognosis in breast cancer patients. Clin. Cancer Res., 8, 1167-1171.

Mizuta, S., Ito, Y., Kohno, A., Kiyoi, H., Miyamura, K., Tanimoto, M., Takamatsu, J., Naoe, T., Morishima, Y., Ueda, R. \& Saito, H. (1999) Accurate quantitation of residual tumor burden at bone marrow harvest predicts timing of subsequent relapse in patients with common ALL treated by autologous bone marrow transplantation. Nagoya BMT Group. Bone Marrow Transplant., 24, 777-784.

Neale, G.A., Coustan-Smith, E., Stow, P., Pan, Q., Chen, X., Pui, C.H. \& Campana, D. (2004) Comparative analysis of flow cytometry and polymerase chain reaction for the detection of minimal residual disease in childhood acute lymphoblastic leukemia. Leukemia, 18, 934-938.

Nyvold, C.G., Stentoft, J., Braendstrup, K., Melsvik, D., Moestrup, S.K., Juhl-Christensen, C., Hasle, H. \& Hokland, P. (2006) Wilms' tumor 1 mutation accumulated during therapy in acute myeloid leukemia: Biological and clinical implications. Leukemia, 20, 2051-2054.

Ogawa, H., Tamaki, H., Ikegame, K., Soma, T., Kawakami, M., Tsuboi, A., Kim, E.H., Hosen, N., Murakami, M., Fujioka, T., Masuda, T., Taniguchi, Y., Nishida, S., Oji, Y., Oka, Y. \& Sugiyama, H. (2003) The usefulness of monitoring WT1 gene transcripts for the prediction and management of relapse following allogeneic stem cell transplantation in acute type leukemia. Blood, 101, 1698-1704.

Ogawa, H., Tsuboi, A., Oji, Y., Tamaki, H., Soma, T., Inoue, K. \& Sugiyama, H. (1998) Successful donor leukocyte transfusion at molecular relapse for a patient with acute myeloid leukemia who was treated with allogeneic bone marrow transplantation: importance of monitoring of minimal residual disease by WT1 assay. Bone Marrow Transplant., 21, 525-527.

Ommen, H.B., Nyvold, G.C., Breaendstrup, K., Andersen, B.L., Ommen, I.B., Hasle, H., Hokland, P. \& Østergaard, M. (2008) Relapse prediction in acute myeloid leukaemia patients in complete remission using WT1 as a molecular marker: developement of a mathematical model to predict time from molecular to clinical relapse and define optimal sampling intervals. Br. J. Haematol., 141, 782-791.

Sotobori, T., Ueda, T., Oji, Y., Naka, N., Araki, N., Myoui, A., Sugiyama, H. \& Yoshikawa, H. (2006) Prognostic significance of Wilms tumor gene (WT1) mRNA expression in soft tissue sarcoma. Cancer, 106, 2233-2240.

Trka, J., Kalinová, M., Hrusák, O., Zuna, J., Krejcí, O., Madzo, J., Sedlácek, P., Vávra, V., Michalová, K., Jarosová, M., Starý, J.; For Czech Paediatric Haematology Working Group. (2002) Real-time quantitative PCR detection of WT1 gene expression in children with AML: prognostic significance, correlation with disease status and residual disease detection by flow cytometry. Leukemia, 16, 1381-1389.

Ueda, T., Oji, Y., Naka, N., Nakano, Y., Takahashi, E., Koga, S., Asada, M., Ikeba, A., Nakatsuka, S., Abeno, S., Hosen, N., Tomita, Y., Aozasa, K., Tamai, N., Myoui, A., Yoshikawa, H. \& Sugiyama, H. (2003) Overexpression of the Wilms' tumor 
gene WT1 in human bone and soft-tissue sarcomas. Cancer Sci., 94, 271-276.

van der Velden, V.H., Boeckx, N., Gonzalez, M., Malec, M., Barbany, G., Lion, T., Gottardi, E., Pallisgaard, N., Beillard, E., Hop, W.C., Hoogeveen, P.G., Gabert, J., van Dongen, J.J.; Europe Against Cancer Program. (2004) Differential stability of control gene and fusion gene transcripts over time may hamper accurate quantification of minimal residual disease-a study within the Europe Against Cancer Program. Leukemia, 18, 884-886.

Weisser, M., Kern, W., Rauhut, S., Schoch, C., Hiddemann, W., Haferlach, T. \& Schnittger, S. (2005) Prognostic impact of RT-PCR-based quantification of WT1 gene expression during MRD monitoring of acute myeloid leukaemia. Leukemia, 19, 1416-1423. 